\title{
MODELS OF QUALITY MANAGEMENT APPLIED TO ORGANIZATIONS SEEKING TO INNOVATION MANAGEMENT
}

Tatiane Sartori Production Engineering Department, Federal University of Santa Maria, Brazil

E-mail: tatianesartori@yahoo.com.br

Dr. Eng. Dipl. Wirt.-Ing. Andreas Dittmar Weise Production Engineering Department, Federal University of Santa Maria, Brazil E-mail: tatianesartori@yahoo.com.br

Submission: $21 / 02 / 2013$

Resubmit: 25/02/2013

\section{ABSTRACT}

Accept: 27/02/2013

The Total Quality Management seeks constant improvement and a gradual introduction of new processes both as existing in order to achieve greater excellence in quality organizations as a whole. The intensity of global competition has required companies to rethink their strategies in order to increase competitiveness, profitability and at the same time, thrive on the market that work. To have a management development it is necessary to supplement with quality tools, and management tools, which help in the overview of the organization and also the processes and services. This paper uses the Excellence Management Model (MEG) as a tool to analysis of quality, innovation, productivity and competitiveness in a micro services company located in the central region of the State of Rio Grande do Sul, Brazil. The paper will analyze how the company works with the criteria of the tool used focusing the process of innovation and competitiveness. The study is quantitative and descriptive character type. The bibliographic search is used to build the base of analysis and data collection was accomplished by using a questionnaire with open questions.

Keywords: Innovation Management, Models of quality management, Innovation and Competitiveness. 
DOI: 10.14807/ijmp.v4i1.56

\section{INTRODUCTION}

The organizations today are facing major challenges as the new demands of consumer markets, globalization, increased competition, technological, environmental and social constraints and competition for scarce resources. This form of administration requires more than ever for organizations to improve their business management in order to achieve improvement of its processes and outcomes. The continuous improvement has been one of the important factors in the development of organizations, for quality management advocates the development of good results and actions within organizations.

In the past, productivity growth was due to the value of the investment in infrastructure and new technologies installed, in other words, the higher the value invested in technology, greater productivity. Currently, important part of productivity growth, not only the economies, but also in developing countries, due to innovation. Innovate means answering the demands of the markets, compete, you deploy the methodologies and promote innovation management so that this theme is central in the competitive strategies of organizations.

Understand what is innovation and how it happens becomes of great importance because from this context one can leverage new concepts and understanding of the subject this being discussed not only in organizations, but also in areas of research and development. In 1962, in Italy, was released the Frascati Manual, which describes innovation as the successful introduction on the market of products, services, processes, methods and systems that previously did not exist or containing some feature new and different from the hitherto in force. Includes activities as scientific, technological, organizational, financial, commercial and marketing reasons. The minimum requirement is that the product/process/method/system to be new or substantially improved for the company in relation to its competitors. Likewise, in 1990, was released the Oslo Manual, which defined innovation as the implementation of a product (good or service) new or significantly improved, or a process, or a new marketing method, or a new organizational methods in business practices, workplace organization or external relations.

This work uses the Management Excellence Model (MEG) as a tool for the analysis of quality, innovation, productivity and competitiveness in a micro services 
company located in the central region of the State of Rio Grande do Sul, Brazil. The goal is to identify and analyze how the company works with the criteria used tool focusing on the processes in the model and the PDCA cycle. The MEG is a management model used by the National Quality Foundation (FNQ), which is a national center for study, debate and irradiation of knowledge about management excellence and promotes a comprehensive understanding of the requirements to achieve performance excellence improved competitiveness. The model is based on eight criteria: Leadership, Strategies and Plans, Customers, Society, Information and Knowledge, People, Process.

The study is a quantitative and descriptive character. The literature review is used to build the basis of analyzing the proposal. Gil (2009) describes this type of research to be developed from materials already developed, consisting primarily of books and scientific articles. To get the desired results data collection was conducted through a questionnaire followed by a case study in the studied company where Gil (2009) describes this method as the deep and comprehensive one or a few objects in search of widely known and detailing the same. Finally, there was the evaluation of data through the proposed model and present the results and conclusions.

\section{MANAGEMENT OF INNOVATION AND QUALITY}

An innovative organization and therefore competitive depends on a value chain with great adaptability, willing to break paradigms to get good results that ensure the sustainability of each company. As Terra (2007), the culture of innovation throughout the value chain is one of the factors responsible for preserving competitiveness and survival of organizations. The value generated can be expressed in several ways, such as: economic value, strategic value or other value that is important to the company.

Innovation is not only associated with the speed required in highly competitive environments (TIDD; BESSANT; PAVITT, 2008). It is present in simple or complex systemic solutions, or not, simple observations or casualty of complex analysis. Those cites that "innovation must not be restricted to areas of research and development, but cover all aspects of business and processes, to increase the ability to respond to external and internal stimuli, with originality, so as to generate favorable results in the pursuit of performance excellence and competitiveness". 
Many companies use the innovation management to increase its work to innovate. Companies that understand the importance of the critical role for the formation of a culture of innovation and competitiveness also understand that to get good ideas is to get lots of ideas and all people, regardless of their hierarchical level, can contribute with good ideas. People who have their projects implemented identify themselves more with their work and the more important than reward the employee is evaluated with rapidity and transparency to their ideas. (TERRA, 2007)

Quite simply, innovations mean taking a new idea, or sometimes apply the ideas of others in news or a new shape. Innovation is the specific instrument of entrepreneurship. Means to have a new idea, or, apply the ideas of others in an original way and with effectiveness. (TERRA, 2007) An existing idea can be done differently or through a new situation, it is not necessary to innovate with something new, and may take the innovation in various ways. (SCHUMPETER 1982). Innovation is driven by knowledge in constant acceleration, significantly contributing to the destabilization and change. (LASTRES et al, 2005). Is a process, not an isolated event, and must be managed as such. Influences on these processes can be manipulated to affect the outcome, i.e. the innovation can be managed. It's not just good ideas, but a combination of the same with a motivated team and an instinctive understanding of what the customer needs. Innovation is more than simply designing a new idea, is the process of developing practical usage. (TIDD; BESSANT; PAVITT, 2008)

Thus, within the field of innovation management, the analysis may be made in the same perspective. Hult et al. (2004), for example, defines innovation as "the way to change the Organization, as a response to external or internal changes or as a proactive attempt to change this environment". Hult et al. (2004), asserting that, "how the environment is changing, companies must adopt innovations over time and, more importantly, innovations are those activities that enable the company to obtain competitive advantages," thereby contributing to business success and effectiveness. Thus, innovation is considered one of the "key processes" that strategic can help companies to adapt both internally and externally. However, the conceptual relationship between innovation and strategic alignment practices is not yet well understood, as the different terminology and models make it difficult to establish the relationship between different concepts (FERREIRA, 2005). 
Many companies use the Innovation Management to enhance their work to innovate. Companies that understand the important role critical to the formation of a culture of innovation and competitiveness also understand that to have good ideas you must have many ideas and all people, regardless of their hierarchical level, can contribute good ideas. People who have implemented their projects identify more with their work and more important than reward the employee is a quick and transparent evaluate their ideas (TERRA, 2007).

Successful innovations rarely require a lot of money in the early stages and crucial. But require some people very competent, dedicated, motivated, working fulltime and hard (DRUKER, 2007). In this context, one can see how important it is for organizations to prioritize the training of human resources, training them and developing them constantly, both in technical expertise, as well as administrative, technological knowledge, services and others.

Second Terra (2007) excellence in innovation must incorporate the planning, development and implementation of programs, processes and competitive activities that protect organizations of obsolescence's, are internal, or those caused by environmental changes. Therefore, to manage business models or innovations requires a separate business management of day to day operations, with a differentiated Profile Manager. For this it is necessary that the Organization set as well who is going to lead this area and to whom that person will report.

Simply put, innovation means having a new idea, or sometimes apply the ideas of others in new or in a new way. Innovation is the specific instrument of entrepreneurship. It means having a new idea, or, apply the ideas of others in an original way and effectively (TERRA, 2007). An idea already existing may be performed in a different manner or by means of a new situation and it is not necessary to innovate with something new, the innovation may take various forms (SCHUMPETER, 1982). Innovation is driven by knowledge in constant acceleration, contributing significantly to the destabilization and change. (LASTRES et al, 2005). It is a process, not an isolated event, and must be managed as such. The influences on these processes can be manipulated to affect the outcome, ie, innovation can be managed. It's not just good ideas, but a combination thereof with a motivated team and an instinctive understanding of what the customer needs. Innovation is more 
than just designing a new idea, is the process of developing practical use. (TIDD; BESSANT; PAVITT, 2008)

Transform an organization into a highly innovative space calls for adopting some set of actions on how we create, learn and create value. Without risk there is no innovation, but for some people break the rules, failure or failed attempts are not rewarded. With so many ideas that could add value are stored for fear of making mistakes and insecurity (TERRA, 2007). Some organizations, for working with instant results, just not allowing employees to work on new ideas, but how to create an environment for idea generation if new ideas are not respected? The companies working with management recognize that this is an inherent aspect of innovation and develop risk-sharing mechanisms to reduce the impact of loss.

In the knowledge era managers need to be humble enough to recognize that no longer have the necessary knowledge to conduct all operations of their companies. In some sectors more dynamic, managers can barely understand how some new technologies actually work and, in others, it takes many years to master the various technical aspects related to the functioning of a single machine. Anyway, whatever the sector of the economy, good managers are mainly motivating human potential to engage the body, mind and soul at work.

According to Pereira (2007) for excellence in innovation should incorporate planning, development and implementation of programs, processes and competitive activities that protect organizations from obsolescence, are the internal, or those caused by environmental changes. Therefore, to manage business models or management innovations required separate business operations day to day, with a different profile manager.

\section{MODEL MANAGEMENT EXCELLENCE - MEG}

The Management Excellence Model $®(M E G)$ is a management model used by the National Quality Foundation (FNQ), which is a national center for study, debate and irradiation of knowledge about management excellence. The MEG has the main feature being a systemic model which consolidates the best management practices aimed at leading organizations in their respective areas. He is an internationally recognized full model, targeted at business results, promoting 
organizational learning. Emphasizes the systemic integration and alignment, which allows management maturity. (FNQ, 2012).

For the MEG is implemented is necessary that the basis of criteria are deployed within an assembly capable of expressing a business logic, so criteria are understood as follows:

1. Leadership - Discusses the management processes for the philosophical orientation of the Organization and external control over its direction, engagement, leadership and control of Direction results.

2. Strategies and plans - Managerial processes related to the design and implementation of strategies, including the establishment of targets and the definition and follow-up of the plans necessary for the success of the strategies.

3. Customers - Covers management processes of customer information, and market and communication with the market and customers and prospects.

4. Society - This criterion aims management processes regarding treatment and demands of society and the environment.

5. Information and knowledge - Organized treatment demand for information in the Organization and development of controlled intangible assets of generators, especially the competitive differentiators of knowledge.

6. People - High-performance teams configuration, development of competences of persons and the maintenance of their well-being.

7. Proceedings - This is the main processes and support to business.

8. Results - Discusses the Organization's results in the form of historical series and relevant comparative benchmark accompaniments.

The adoption of MEG by an organization is a continuous and evolving process. This process is depicted in Figure 1 (FNQ, 2012).

From the critical analysis of opportunities for improvement, the organization defines the improvement plans. These plans have priority considering the impact on performance, viability and capacity of the organization to put them into practice. Some are immediate, others implemented in daily processes. It needs to be a revision of actions performed for refinement of the process of self-evaluation to a new cycle. 


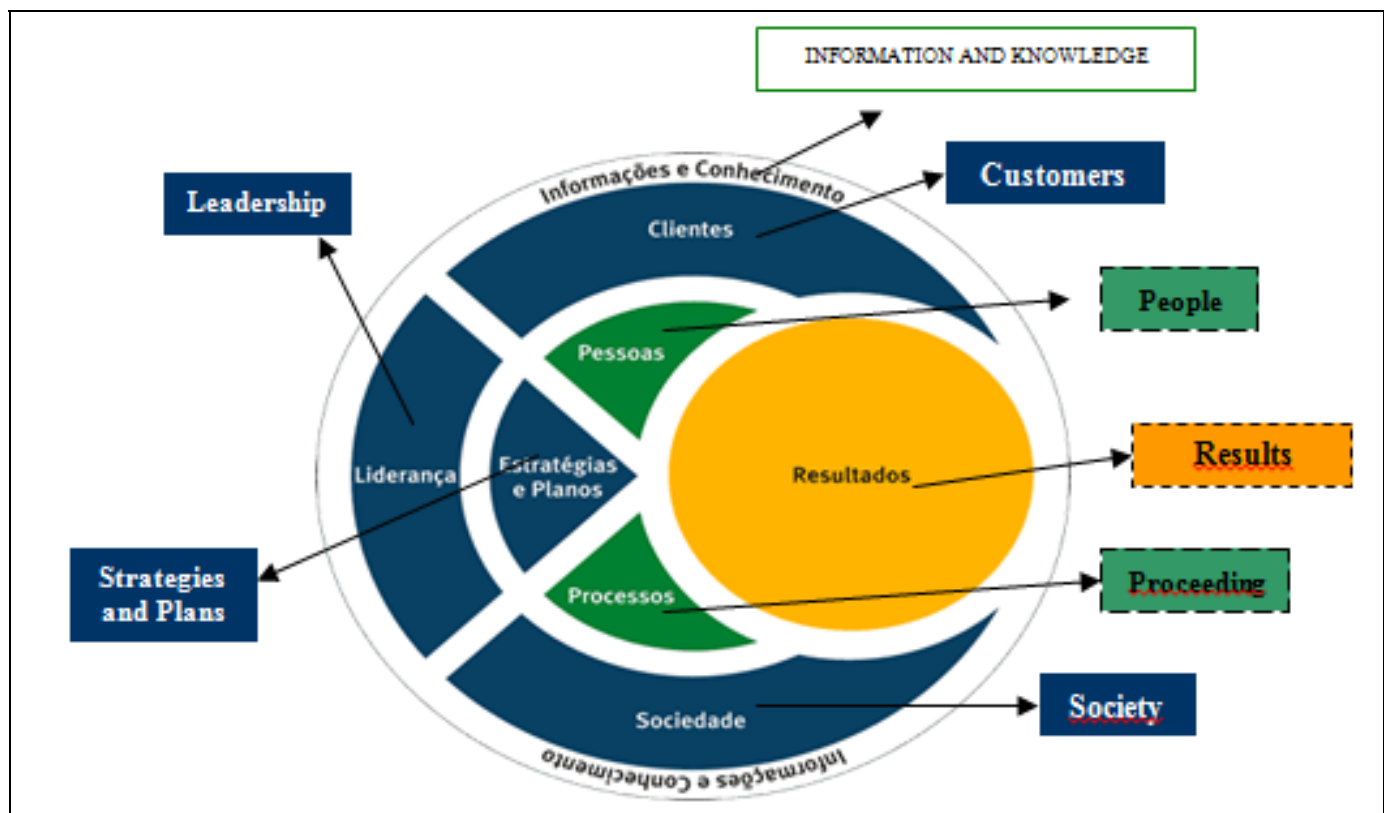

Figure 1: Adapted by Management Model of Excellence (MEG)

The Management Excellence Model $®$ (MEG) is based on eleven (11) submissions and eight criteria. How foundations can define the pillars, the theoretical basis of good management. These foundations are put into practice through the 8 (eight) criteria. The Management Excellence Model ${ }^{\circledR}-$ MEG is based on the following grounds (FNQ, 2012):

1. Partnership Development - Development of joint activities with other organizations from the full use of core competencies of each, aiming to benefit both parties.

2. Systems Thinking - Understanding the interdependencies among the different components of an organization and between the organization and the external environment.

3. Organizational Learning - Searching achieve a new level of knowledge for the organization by means of perception, reflection, evaluation and sharing of experiences.

4. Culture of Innovation - Promoting an environment conducive to creativity, experimentation and implementation of new ideas that can generate a competitive advantage.

5. Leadership and Constancy of purpose - Acting in an open, democratic, inspiring and motivating people, aiming to develop a culture of excellence, the promotion of quality relationships and protecting the interests of stakeholders. 
6. Vision for the future - Understanding factors that affect the organization, its ecosystem and the external environment in the short and long term.

7. Guidance and information processes - Understanding and targeting of all the organization's activities and processes that add value to the stakeholders, and decision-making and execution of actions must be based on the measurement and analysis of performance, taking into consideration the available information, and include the risks identified.

8. Valuing People - Creating conditions for people to undertake professional and humanly, maximizing their performance through commitment, skills development and space to undertake.

9. Knowledge about the customer and the market - Knowledge and understanding of customer and market, aiming to create sustained value for the customer and thereby generating greater market competitiveness.

10. Social Responsibility - Acting as defined by the ethical and transparent organization with all stakeholders with whom it relates. It also refers to the insertion on a sustainable development of society, preserving environmental and cultural resources for future generations, respecting diversity and promoting the reduction of social inequalities as part of the organization's strategy.

11. Delivering Value - Scope consistent results by increasing tangible and intangible value in a sustainable way for all stakeholders.

The first seven criteria dealing with the management processes, the latter criterion is related to results obtained by the organization, as shown in Figure 2.

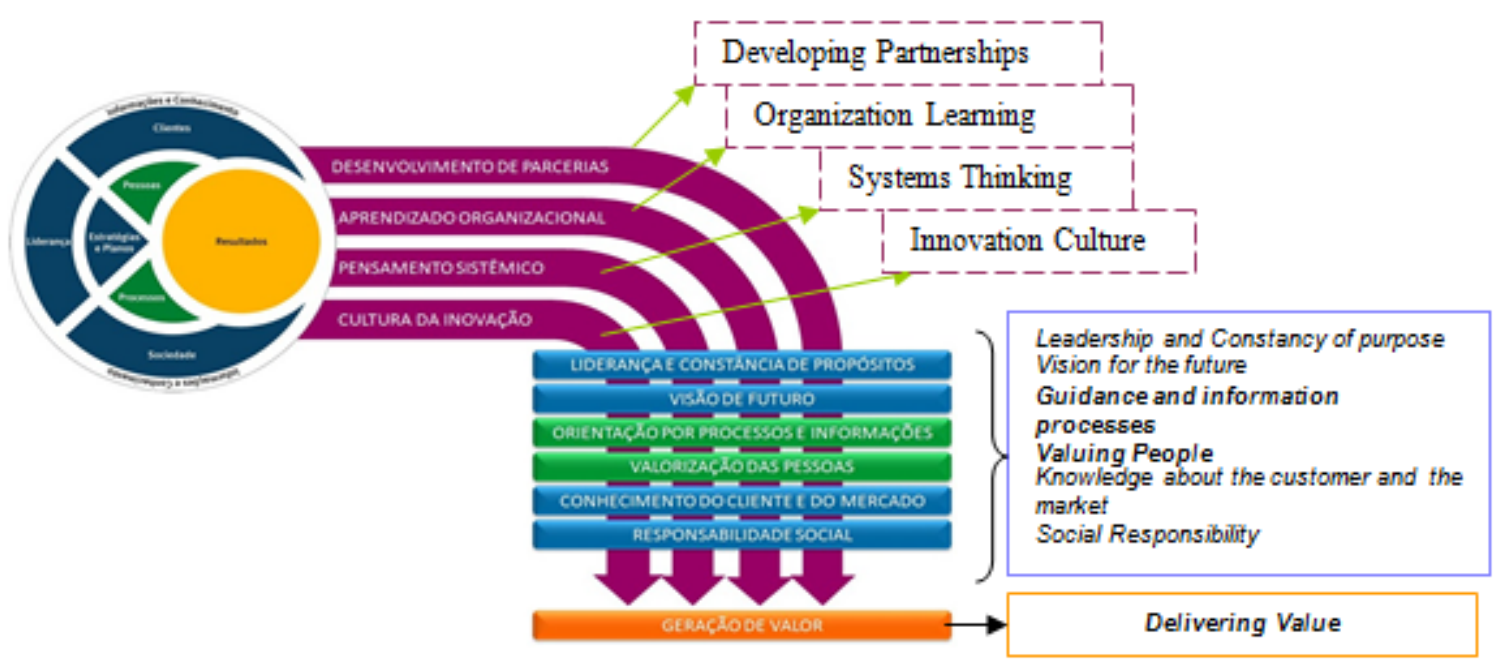

Figure 2: Adapted by Fundamentals of Management Excellence Model $®$ - MEG 
The MEG symbolizes the organization, considered as an organic system, adaptable to the external environment and organizes its eight criteria for systemic form, indicating your character interdependent and complementary, aiming to generate results. The MEG uses the concept of learning, according to the $\mathrm{PdCl}$ cycle (Plan, Do, Check, Learn). (CIRIBELI, ANDRADE, 2011)

Plan means seek to identify, understand and meet customer expectations and needs of society. In this case, the leader's role is extremely important, both in performance analysis as in the execution of actions. They determine the competitive position and deploy this strategy into action plans for the short, medium or long term, allocating resources to ensure the implementation of the strategies. In making the step, the process involves people and processes. People must be empowered and satisfied, acting in an environment conducive to the consolidation of a culture of excellence, so that processes are executed as planned. Control means checking, analyzing, what is being put in place to ensure that the whole cycle takes place smoothly. At this stage the results are measured in relation to economic, market and customers, people, society, processes and suppliers. And finally learn, that are established in the form of information and knowledge, so there is execution of actions and the pursuit of organizational learning. This information represents the intelligence of the organization, enabling performance analysis and taking the necessary actions (NECS, 2013).

The PDCA is a cycle of development that focuses on continuous improvement. It is applied to achieve results within the processes and can be used in any organization, regardless of practice area. Specifically for Data Management, it can be applied practically in all cases.

As the figure 3, the cycle begins for planning ( $P$ - Plan), then the action or set of actions planned are executed ( $D$ - Do), checks whether what was done was according to plan, constantly and repeatedly ( $\mathrm{C}$ - Check), and takes up an action to eliminate or at least mitigate the problems encountered in the implementation of the product or process (A - Act). (NECS, 2013; FNQ, 2012) 


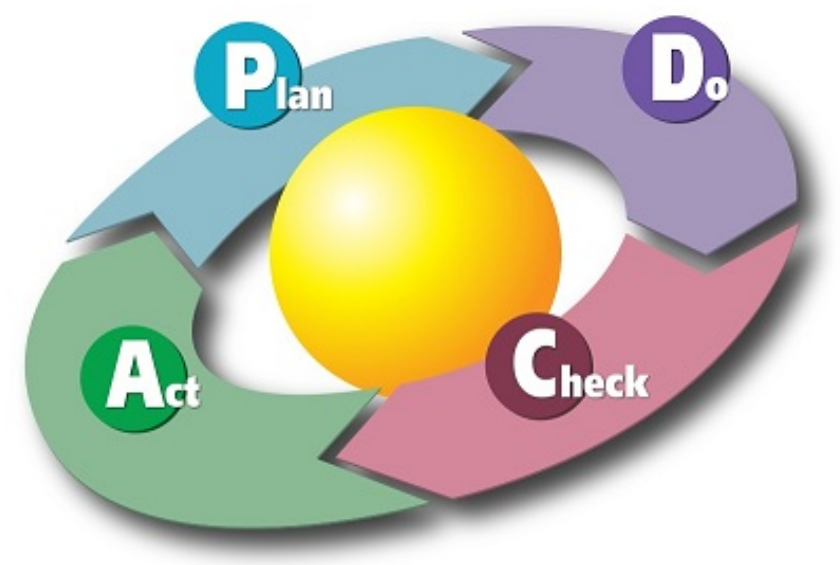

Figure 3. Center for Excellence in Research and Development (NECS, 2013)

The whole cycle $\mathrm{PdCl}$, when run, will lead to results, which should be analyzed and understood, generating information and knowledge to be used in the decisionmaking process, generating a new cycle management. The strategies are deployed into action plans that address all levels of the organization. For these strategies can be implemented, should be allocated the necessary resources, taking into account the capacity of the organization. To control the results of the action plans are defined performance indicators, compared with the targets set, will guide any course corrections that are necessary, updating plans (FNQ, 2012).

Any organization adopting the MEG can plan their management practices based on the requirements of the Criteria for Excellence, evaluate them and improve them systematically them continuously for all processes, products, and stakeholders. One of the main features of MEG is that it is a systemic model, ie, considers the structuring and alignment of the components of organizational management from the perspective of a system. Thus, it allows the various elements of an organization can be implemented and evaluated together in an interdependent and complementary, to align management systems to leverage results. The model can be used in evaluations, diagnoses and guidelines of any type of organization (of different sizes, whether public or private, or nonprofit).

The MEG provides a framework for managing organizations, which is used annually based on management practices of World Class organizations, is targeted to business outcomes, promotes organizational learning, emphasizes the systemic integration and alignment.

\section{METHODOLOGY OF THE STUDY}


In order to verify the compatibility of the proposed model to the reality of the studied company adopted the methodology of single case study. As regards the nature of the research, work was characterized as qualitative. According to Mattar (1999), qualitative research identifies the presence or absence of the object studied. Moreover, qualitative research, data are collected through group or individual research through in-depth interviews and specific.

In the case of this study, before the implementation of the tool was an interview with the Director of the organization, taking into account the opinion and knowledge of the respondent, where it answered questions with open-ended questions, seeking reply on various topics, as well as firm characteristics, strategies and management, leadership, technology, competitors, policies and practices of human resources, innovation in services and processes and marketing. For Gil (2009), the subjects of an experiment develop their actions in a certain environment. It is important to apply research that subjects have knowledge about the environment and that he has authority and notoriety to answer on the proposed topic.

Later there was the application of the Model of Excellence in Management in the company whose business in a micro services company located in the central region of the State of Rio Grande do Sul, Brazil, identifying innovation as a key business success factors and processes as well as the expertise of its employees with the quality of care and services offered.

\section{ANALYSIS OF THE RESULTS}

As described earlier, the model used by research aims to eight points, all of which were analyzed through inquiries made to the managers and other employees of the organization. The eight points are: customers, society, leadership, strategies and plans, people, processes, and information and knowledge.

As the clients, the organization plans to the grouping of the same and the information is used to better serve existing customers and attract new ones. The customers' needs and expectations are known based on customers ' information utilizing computerized methods. Services and products are made available to customers via the Organization's Web site, as well as sending emails with available services. As complaints, are logged, resolved and given a customer return, aiming at greater interaction between customer and organization. Customer satisfaction is evaluated at regular intervals, through formalized methods (questionnaires) and the 
results obtained are analyzed looking for continuous process improvement. One can see that the company seeks to group planned new customers, thereby, proffer adequate services for each customer group, bearing in mind the importance of maintaining existing customers. The company strives to meet the needs of clients to improve the relationship between the two.

The assessment of the organization in the face of society, as the negative impacts that may be caused to the environment are analyzed by the Board of Directors and is always treated planned to avoid such impacts. There are prevention and counseling for these damages to avoid any kind of negative impact to the environment. The company works with social projects promoting local and regional development, involving all employees in the organization.

The leadership within the organization is clearly held by managers seeking to interact with developers listening your ideas, proposals and questions. There is an acceptance on the part of the leader, as the new ideas and innovations, which are analyzed and implemented wherever possible. The leader of today is no longer the one authoritative person, that rather than listen, sorts and leads a group. These still exist, but are being extinguished in the labour market. Today's leaders, who are occupying the chairs of CEOs, are those who have the voice command, but they know it passes, that know how to retain the best talent in the group, who view the job along with its employees and who know how to make their ideas are supplemented and not simply met by their subordinates. (KNAANE,1999). The Organization studied, information is shared with frequency and are known to everyone. Invest in your development leaders frequently and apply the same in improving processes within the organization. They seek a better relationship with their employees through the search of opinions, ideas and group collaboration.

To set terms defined strategies for achieving the vision of the future and are established indicators, targets and action plans, is used the criterion of strategies and plans, which the mission and vision of the company is writing and knowledge of the Group and ethical behavior is detailed in written rules and easy access to the people who work in the company. The strategies are defined formally through methods that take into account internal and external factors, where the indicators and targets are set for the main strategies, which are disseminated to employees through meetings. With this is set a plan of action to achieve goals and process improvements. 
In criterion people, sought to identify the roles and responsibilities were defined, as well as the activities related to hiring people, training and development of employees. It was noted that the functions and responsibilities (officers and employees) are well-defined through documentation and are known by the employees. Hiring takes into account the needs for the position, as well as the individual characteristics of each for each function. This lessens the improper hiring error, since each developer works in function that shows strengths, improve weaknesses through trainings, are therefore made available accreditation training and constant improvement. Aiming at the well-being of the employee, the company identifies, by means of methods of prevention of environmental risks (PRA) and control Programs of medicine and occupational health (PCMSO), health risks and worker safety, promoting corrective and preventive actions. It is important to maintain a favorable climate in which people can develop their full potential and achieve the achievement at work. Quality of life is directly related to the needs and expectations of the human being and with the achievement of satisfaction of these needs. Has to do with the welfare of the individual in your work environment, your way of expressing relationships healthy and harmonic within the organization. (KNAANE, 1999)

The criterion of search processes to verify whether the company's core processes (services, marketing and production) are executed and how is managing its main suppliers and the company's financial resources. In this context the Organization presents favorable factors, because the main activities are controlled on the basis of implementing standards defined, some controlled by indicators and targets, where processes are defined and documented. As for suppliers, they are selected with defined criteria and performance is evaluated periodically, generating actions for improvement where necessary. The company's financial control is accomplished through a cash flow and a budget plan with the horizon of at least one year.

The last criterion, that is information and knowledge, seeks to identify how it is used the information necessary for the implementation of the activities of the company, including comparative information to assist in the analysis and improvement of its performance. The company works with the information defined and organized through an information system is in-house for developers, is external 
to customers and suppliers. This information is evaluated, compared and used as a way to improve the services, products and processes within the organization.

\section{FINAL CONSIDERATIONS}

From the study becomes visible the importance of innovation management in organizations, being this a competitive differentiation factor between businesses and their markets. Whereas the main objective of the study was to examine whether the company studied was acting in accordance with the criteria of the tool used focusing the process of innovation and competitiveness, realizes that there is harmony between the criteria and how the company manages its processes. Innovation is perceived on the criteria of people, when the organization supports and stimulates the creation of new ideas, as well as search listen any questions and complaints by employees. It is also perceived in the discretion of customers when the company assists, quickly and accessible customer service problems and gives feedback on the faults in processes, seeking the assertiveness and the improvement in attendance. Creating programs to assist in these calls and clients also concern about the Organization's processes, shows us that the company has a desire to increase its innovation, seeking the competitiveness on the market it operates.

The tool provides a comprehensive view of the Organization, from the developer's role within the company until the administration of high Head. The leader has an important role within the Organization, because it does not coordinate only processes, but also people why the need for an innovative leader, motivator and interested in the opinion of our customers, both internal and external.

Through this study, realizes that the company studied is in search of improvements in innovation, and constant growth in order to increase their competitiveness on the market. In today's market is not sufficient only to innovate, you have to compete. Competitiveness and innovation go together to cover markets and increase opportunities. So there is this understanding, it is necessary for organizations to know manage strategies that make their products are innovative and can compete with results, adding value to the final consumer.

Thus, the present study was able to pursue this research questioned aspects realizing the innovation management and management of excellence work together for the development of business and the company studied the search in their 
INDEPENDENT JOURNAL OF MANAGEMENT \& PRODUCTION (IJM\&P)

improvement and innovation processes, thereby increasing your chances on the market that is increasingly competitive. Identify which are the points on which companies must improve causes the innovations are identified faster and the negative points are worked out, through a clear strategic alignment and safe.

\section{REFERENCES}

CIRIBELI, J. P; ANDRADE, C, M; (2011). A aplicação do PDCA como metodologia de redução do índice de falhas no processo produtivo da Itatiaia Móveis S/A. Gestão Empresarial Paper, v1, n.1.

DRUKER, P. (2007). Innovation and Entrepreneurship: practices and principles. New York: Harper and Row.

FERREIRA, V. C. P. et al. (2005). Modelos de gestão. Série Gestão de Pessoas. Rio de Janeiro: FGV.

FUNDAÇÃO NACIONAL DA QUALIDADE - FNQ. (2012). Conceitos Fundamentais da Excelência em Gestão. Available: http://www.fnq.org.br/site/292/default.aspx . Access: 10/02/2013.

FUNDAÇÃO NACIONAL DA QUALIDADE - FNQ. (2012) Modelo da Excelência da Gestão. Available: http://www.fnq.org.br/site/376/default.aspx . Access: 10/02/2013.

GIL, A. C. (2009). Projetos de Pesquisa. São Paulo: Atlas.

HULT, G. T. et al. (2004). Innovativeness: Its antecedents and impact on business performance. Industrial Marketing Management. Volume 33.

KNAANE, R. (1999). Comportamento humano nas organizações: O homem rumo ao século XXI. 2. ed. São Paulo: Atlas.

LASTRES, H. M. M.; CASSIONATO, J. E.; ARROIO, A. (2005) Conhecimento, sistemas de inovação e desenvolvimento. Rio de Janeiro: UFRJ.

MATTAR, F. N. (1999) Pesquisa de marketing: metodologia, planejamento. São Paulo: Altas.

MOVIMENTO BRASIL COMPETITIVO - MBC. (2010) Questionário de Autoavaliação ciclo 2010. Available: http://www.mbc.org.br/mpe/ Access: 27/05/2012.

NÚCLEO DE ESTUDOS CIENTíFICOS EM SUSTENTABILIDADE - NECS. (2013). Ciclo PDCA, abordagem de processo e escopo do sistema de gestão ambiental. Available: http://necs. preservaambiental.com/ciclo-pdca-abordagem-de-processo-eescopo-do-sistema-de-gestao-ambiental/. Access: 10/01/2013.

PEREIRA, H. J. (2007) Os novos Modelos de Gestão: Análise e algumas práticas em empresas brasileiras. These (Administration). São Paulo: EAESP-FGV. Available: http://hdl.handle.net/10438/4577. Access: 08/01/2013.

SCHUMPETER, J. A. (1982) Teoria do desenvolvimento econômico. São Paulo: Abril Cultural.

TERRA, J. C. C. (2007) Inovação. Quebrando paradigmas para vencer. São Paulo: Saraiva.

TIDD, J.; BESSANT, J.; PAVITT, K. (2008) Gestão da Inovação. Porto Alegre: Bookman. 